\title{
Executive Shareholding and Ambidextrous Innovation the Moderating Effects of Executive Education and Executives Term
}

\author{
Wei Mengli ${ }^{1,2 *}$ Zhu Yongming $^{1}$
}

\author{
${ }^{1}$ School of Management Engineering, Zhengzhou University, Henan, Zhengzhou 130021, China \\ ${ }^{2}$ Management Engineering, Zhengzhou University, Henan, Zhengzhou 130021, China \\ *Corresponding author. Email: 1576635294@qq.com
}

\begin{abstract}
Taking the listed companies in 2015-2018 as a sample, the paper discusses the influence of the shareholding ratio of senior executives on the enterprise's dual innovation, and examines the adjustment effect between the senior management qualifications and the senior management term. Through research, it is found that executive stock holding can promote the use of innovation, but there is no significant positive correlation with exploratory innovation; executive education plays a regulatory role between executive stock ownership and corporate use innovation; The term of executive management has played a regulatory role between executive shareholding and exploratory innovation. From the perspective of senior management, this paper studies the internal mechanism of its influence on enterprise dual innovation, further enriches the theoretical content of dual innovation, and has important practical guiding significance for enterprises to carry out innovation activities.
\end{abstract}

Keywords: Executive Shareholding, Executive Education, Executives Term, Exploratory Innovation, Exploitative innovation

\section{INTRODUCTION}

In recent years, the trade war between China and the United States has become increasingly fierce. For example, in 2018, the us department of commerce announced that us companies would be banned from selling software and technology to ZTE for the next seven years, and ZTE would pay up to $\$ 1.4$ billion in compensation after its "broken core". Ma huateng, chairman and CEO of tencent, has commented on the zte incident, saying it highlights the urgency for China to develop its own chip industry. On May 17, the United States blacklisted Huawei and cut off the supply of american-made software and parts for its products. The influence of these external factors reflects the importance of enterprises' independent innovation ability.

On May 22, 2019, general secretary Xi jinping proposed at the symposium on promoting the rise of central China that "technological innovation is the lifeblood of an enterprise". Therefore, enterprises need to develop technology into their core competitiveness so as to extend their life cycle. On July 10, 2018, WIPO and INSEAD jointly issued the global innovation index report (GII) "in 2018, the report pointed out that for the first time in our country into the world's top 20 most innovative economy, this shows that our country in recent years, vigorously implement the strategy of innovation driven development, promote the" public entrepreneurship, people's innovation "has made significant achievements. In order to maintain a relatively sustainable and stable development in a highly uncertain environment, enterprises not only need to rely on existing technology, knowledge and other resources for relatively less obvious utilization innovation to protect their existing market position. What's more, it is necessary to make bold attempts to make full use of brand-new knowledge and ability to break through the existing technology field and make substantial innovation in another technology field completely different from the original technology field that the enterprise belongs to, so as to realize the long-term sustainable growth of the enterprise economy. Compared with exploitative innovation, exploratory innovation has greater uncertainty and higher risk of failure. Therefore, under normal circumstances, enterprise managers are more inclined to implement exploitative innovation.

\section{RESEARCH STATUS}

\subsection{Executives at Stake}

Through literature analysis and summary of the research on senior management shareholding, this study discusses from the following two aspects. First, there are different opinions among different scholars on the definition of senior management. For example, some scholars believe that all senior managers should be included in the scope of 
senior executives [2], while others believe that only senior managers above the level of vice President can be considered as senior executives [3]. Other scholars define the directors, supervisors and senior managers disclosed in the annual report as the executives of listed companies [4]. Secondly, there has been no consistent conclusion about the research on the relationship between executive shareholding and innovation in the academic community, which includes both positive correlation and negative correlation. For example, research results show that ceos holding shares are more willing to carry out r\&d activities than ceos not holding shares. In other words, senior executives holding shares can stimulate managers to carry out technological innovation [5]. But there is also the opposite argument, that stock incentive schemes will cause managers to cut back on innovation [1]. It can be seen from previous studies that the current research on executive shareholding is still not systematic, and the effect of executive shareholding on innovation, namely the impact mechanism, still needs further theoretical research.

\subsection{Executive Education}

Generally speaking, a person's education level represents the person's education level. Therefore, the higher the education level and the higher the education level of executives, the better their professional knowledge and problem-solving ability, and the more inclined they are to make decisions that are beneficial to the organization. Some scholars have found that a person's own software conditions, such as birth and education experience, will determine the way of doing things [6]. In previous studies on the relationship between executive education and enterprise innovation, the conclusion is roughly the same, that is, the executive education can significantly promote enterprise innovation [7-8]. However, in the context of dual innovation, few scholars have been involved in the influence of executive education on it. Therefore, this study introduces the important variable of executive education, and probes into the mechanism of executive education in dual innovation.

\subsection{Executive Tenure}

The qualifications of management personnel and time to a certain extent, can reflect the management level of experience, through the literature reading and sorting, found that in the past research on executive tenure concerns mainly is the term for the enterprise r\&d spending, tenure, and the influence of the change of the relationship between human capital and the relationship between enterprise performance. As for the relationship between tenure and r\&d expenditure, foreign scholars have studied that the longer the senior executives stay in office, the less desire and motivation they have for r\&d investment, because the long tenure leads to the senior executives' preference for more stable project investment
[9]. On the study of executive tenure and human capital, it is generally concluded that the longer the tenure of senior executives is, the more human capital they accumulate. Both foreign and domestic scholars have done a lot of research on the relationship between executive tenure and corporate performance, but there are various opinions on the conclusion. However, the research on the relationship between executive tenure and innovation is basically concentrated in the last decade or so. From the perspective of corporate governance, the original innovation of enterprises will be affected by executive tenure [10] Therefore, this study introduced the important variable of tenure of senior executives to deeply explore the mechanism of tenure of senior executives in dual innovation.

\subsection{Dual Innovation}

Dual innovation refers to that enterprises should not only meet the current needs but also adapt to the changing dynamic environment in the future [11]. Danneels divides dual innovation into exploratory innovation and utilization innovation [12].Exploratory innovation refers to the innovation carried out by enterprises through the use of new knowledge, new technology and other resources to find opportunities in the market.Utilization innovation refers to the relatively stable innovation behavior conducted by enterprises by using existing knowledge to improve existing technologies or products.The fundamental difference between the two lies in the degree of innovation. On the one hand, it is believed that exploratory innovation and duality are opposite to each other, because they need completely different strategies, organizational structures and capabilities [13].On the other hand, it is believed that the two are mutually complementary, so there are two different views when developing the scale. Since the introduction of dual innovation into the field of management, it has been a research hotspot. The research on the influencing factors of dual innovation mainly includes three aspects: leadership style, organizational learning and knowledge management; The results of dual innovation mainly include two aspects: competitive advantage and performance management. From the perspective of dual theory, this paper intends to study the influence of senior executives' characteristics on dual innovation, so as to supplement the antecessors of dual innovation.

\section{RSEARCH HYPOTHESIS}

\subsection{Senior Management Shareholding and Dual Innovation}

According to the principal-agent theory, there is a considerable inconsistency between the objectives of the operator and the owner of the enterprise, so there may be a 
phenomenon that the operator deviates from the objectives of the shareholder. Incentive theory tells us that if enterprises can design a set of effective incentive mechanism for executives to guide managers' behaviors, thereby coordinating the differences between managers and shareholders, so as to alleviate the agency problem [14], therefore, it is of great significance to study its impact on the dual-innovation of enterprises. Found in the previous scholars research conclusion through the implementation of equity incentive can strengthen enterprise managers' sense of belonging, thus reduce the conflicts of interest between managers and shareholders, the managers are more willing to take the initiative to focus on enterprise long-term development, especially the technology innovation investment, corresponding in dual innovation is to explore innovative, keep the enterprise vitality and energy of constant innovation, leading position and the innovation of the enterprise; When an enterprise is faced with highly uncertain environmental changes, managers will give priority to stabilizing the existing economic benefits of the enterprise, that is, making use of the knowledge and technology possessed by the enterprise's existing human resources for utilization innovation. Based on this, this paper proposes the following assumptions:

H1a: executive shareholding is positively correlated with enterprise exploratory innovation.

H1b: there is a positive correlation between executive shareholding and enterprise utilization innovation.

\subsection{The Moderating Effect of Executive Education on Executive Shareholding and Dual Innovation}

The education of senior executives is their own personal assets. Generally speaking, senior executives' education will bring them higher ability and more acute insight to solve the problems that enterprises will face [15]. Based on this, this paper assumes that the higher the level of education of senior executives, the higher their personal abilities, and the more confident they are. Existing studies have shown that the higher the education level of senior executives, the more strategies they develop will be conducive to the improvement of enterprise performance [16]. High executive education makes managers more confident in their own abilities. Therefore, when the shareholding ratio of senior executives is high, they are more inclined to take an aggressive approach to innovation, that is, to conduct exploratory innovation. On the contrary, for executives with relatively low education background, their confidence will be relatively low. Even if equity incentive is implemented, they are less likely to adopt exploratory innovation, because senior executives are more inclined to adopt more stable utilization innovation. On this basis, this paper proposes the following hypotheses:
$\mathrm{H} 2 \mathrm{a}$ : executive education plays a regulating role between executive shareholding and enterprise exploratory innovation.

$\mathrm{H} 2 \mathrm{~b}$ : executive education plays a regulating role between executive shareholding and enterprise utilization innovation.

\subsection{The Moderating Role of Executive Tenure between Executive Shareholding and Dual Innovation}

In addition to equity incentive and salary incentive, the tenure of senior executives is also an effective incentive mechanism. Generally speaking, the longer a manager stays in the enterprise, the more the shareholders recognize the manager's ability, and the more likely he or she will become a good steward of the enterprise rather than a mere agent [17]. Therefore, the tenure of senior executives and the shareholding ratio of senior executives can play a role in alleviating the agency problem. In addition, previous studies have also verified that managers with a butler style will consider exploratory innovation that can bring future benefits to the enterprise from a long-term perspective. In other words, the longer the tenure of managers, the more likely they are to incorporate exploratory innovation with a longer rate of return into their decision-making scope [18]. When the tenure limit of senior executives is increased, the willingness of senior executives to actively pay attention to the long-term development of the enterprise will be enhanced. If the shareholding ratio of senior executives is increased at this time, senior executives will be inspired to carry out exploratory innovation activities, such as exploring new products or new markets. On the contrary, when the shareholding ratio of senior executives is low, they are less dependent on dividends and have less incentive to carry out exploratory innovation. In this case, if the tenure of senior executives increases, they will invest more energy and financial resources in the utilization of innovation. On this basis, this paper proposes the following hypotheses:

$\mathrm{H} 3 \mathrm{a}$ : executive tenure plays a regulating role between executive shareholding and exploratory innovation.

$\mathrm{H} 3 \mathrm{~b}$ : executive tenure plays a regulating role between executive shareholding and enterprise utilization innovation.

\section{RSEARCH METHODS}

\subsection{Sample Selection and Data Source}

This paper selected listed companies from 2015 to 2018 as the initial samples and screened the data according to the following criteria: missing financial data or abnormal data statistics of listed companies were excluded; Excluding insurance and financial industry samples; Excluding ST, * ST listed companies and extreme companies; We ended up 
with 680 annual observations. The data of the sample company were obtained from CSMAR database of China taian, and the data processing and analysis were completed by Excel and SPSS22.0.

\subsection{Definition of Variables}

Table 1 Selection and definition of variables

\begin{tabular}{|c|c|c|}
\hline Name & Symbol & Variable description \\
\hline Exploratory innovation & ER & Enterprise research expenditures/Total assets at year end $\times 100 \%$ \\
\hline Utilization innovation & EI & $\begin{array}{l}\text { Capitalized expenditures for enterprise development/Total } \\
\text { assets at year end } \times 100 \%\end{array}$ \\
\hline $\begin{array}{l}\text { Shareholding ratio of senior } \\
\text { executives }\end{array}$ & MH & Number of executive shareholding/The total number of shares \\
\hline Executive education & Mdegr & Sum of executive education/Total number of senior executives \\
\hline Executive tenure & Mtime & Total executive tenure/Total number of senior executives \\
\hline The enterprise scale & Size & The natural log of total assets at the end of the year \\
\hline Asset-liability ratio & LEV & The total amount of liabilities/Total assets \\
\hline Enterprise age & Age & Year minus year of establishment plus 1 \\
\hline Return on total assets & ROA & Net profit/Total assets \\
\hline Average executive age & Mage & Sum of executive ages/Total number of senior executives \\
\hline Executive gender ratio & SE & Number of male executives/The total number \\
\hline
\end{tabular}

senior executives, ranging from high school or technical secondary school below $(=1)$ to doctor's degree $(=5)$. The

\subsubsection{Dual innovation}

It includes exploration innovation and utilization innovation. The index of exploratory innovation investment is measured by the expensed expenditure of enterprise $r \& d$ investment, and the index of developmentinnovation investment is measured by the capitalized expenditure of enterprise $\mathrm{r} \& \mathrm{~d}$ investment, which is divided by the total assets to eliminate the influence of scale [14].

\subsubsection{Senior management shareholding}

According to previous studies by foreign scholars Ryan and Wiggins, the ratio between the number of senior executives holding shares at the end of the year and the total number of corporate shares at the end of the year is used to measure [19].

\subsubsection{Executive education and tenure}

Executive education: the education level of senior executives is measured by the highest degree obtained by measurement method is the ratio between the sum of executive education level and the total number of senior executives. Tenure of senior executives: the measurement method is the ratio of the sum of senior executives' tenure to the total number of senior executives [20].

\subsubsection{Control variables}

In this paper, the average age of senior executives and tenure of senior executives are taken as control variables. Meanwhile, the variables of corporate characteristics that influence dual innovation are controlled, such as enterprise size, asset-liability ratio, enterprise age and return on total assets. 


\section{EMPIRICAL ANALYSIS AND RESEARCH HYPOTHESES}

\subsection{Descriptive Statistics}

The descriptive analysis of each variable is shown in table 2 , which mainly includes the minimum, maximum, mean and standard deviation of the sample. It can be seen from the data in the table that there is a significant gap between exploratory innovation and exploitative innovation among the sample companies. The standard deviation of exploratory innovation is 1.744 , the mean value is 1.473 , the maximum value is 19.26, and the minimum value is 0 . The standard deviation of the utilization innovation is 0.698 , the mean value is 0.512 , the maximum value is 5.241 , and the minimum value is 0 . This indicates that the innovation level of different enterprises is different, and there is a big gap between the exploratory innovation and the utilization innovation enterprises. From the comparison of standard deviations between the two, it can be seen that the gap between exploratory innovation is larger than that between pragmatic innovation. The mean value, standard deviation, minimum value and maximum value of the shareholding ratio of senior executives in independent variables are $0.022,0.822,0$ and 0.735 , indicating that the shareholding ratio of senior executives in listed companies is relatively low and the incentive level of equity varies greatly among different enterprises. The standard deviation of executive education background is 0.558 , with a maximum value of 6 and a minimum value of 2 , indicating that there is a significant gap between the educational backgrounds of senior executives. For the tenure of senior executives, the standard deviation is 2.692 , the maximum value is 15 , and the minimum value is 0 . By comparison, it is found that there is a significant difference in the tenure of senior executives in enterprises, and the mean value is 4.369 , indicating that the tenure of most senior executives is relatively low. The last column is the VIF value of the main variables. It can be seen from the table that they are all less than 3 , indicating that there is no obvious collinearity between the variables. The descriptive statistical results of other variables are shown in table 2 .

Table 2 Descriptive statistics of variables

\begin{tabular}{|c|c|c|c|c|c|c|}
\hline Variables & $\mathbf{N}$ & Min & Max & Medium & SD & VIF \\
\hline ER & 680 & 0 & 19.26 & 1.473 & 1.744 & 1.103 \\
\hline EI & 680 & 0 & 5.241 & 0.512 & 0.698 & 1.114 \\
\hline MH & 680 & 0 & 0.735 & 0.022 & 0.822 & 1.184 \\
\hline Mdegr & 680 & 2 & 6 & 3.512 & 0.558 & 1.181 \\
\hline Mtime & 680 & 0 & 15 & 4.369 & 2.692 & 1.251 \\
\hline Size & 680 & 19.916 & 27.469 & 23.113 & 1.523 & 1.676 \\
\hline LEV & 680 & 0.045 & 1.352 & 0.506 & 0.205 & 1.891 \\
\hline Age & 680 & 6 & 37 & 19.50 & 5.254 & 1.169 \\
\hline ROA & 680 & -0.470 & 0.305 & 0.303 & 0.058 & 1.473 \\
\hline Mage & 680 & 40.5 & 63 & 52.013 & 3.462 & 1.279 \\
\hline SE & 680 & 0 & 1 & 0.826 & 0.157 & 1.125 \\
\hline
\end{tabular}

As can be seen from table 3, the regression coefficient of

\subsection{Regression analysis and hypothesis testing}

\subsubsection{Basic model}

This paper measures the influence of senior executives' shareholding on the dual innovation of enterprises, and the basic regression results are shown in table 3 .
$\mathrm{MH}$ of executive shareholding to ER of exploratory innovation is positive, but not statistically significant. In other words, H1a has not passed the test, indicating that there is no positive correlation between executive shareholding and enterprise exploratory innovation. However, there is a positive correlation between executive shareholding and enterprise utilization innovation, and it is significant at the $1 \%$ level, that is, $\mathrm{H} 1 \mathrm{~b}$ has been verified. May be the cause of this phenomenon is: through the analysis of sample data, found that at present our country 
listed company executives in the zero shareholding proportion is as high as $36.77 \%$, the overall differences between executives shareholding is small, the incentive effect is relatively not obvious, so executives high-risk exploratory innovation does not take the initiative, and pressure are more willing to choose low risk using type innovation.

Table 3 Regression result of basic model

\begin{tabular}{|c|c|c|}
\hline Variables & ER & EI \\
\hline MH & $0.051(1.272)$ & $0.105 * * *(2.626)$ \\
\hline Size & $-0.161 * * *(-0.3456)$ & $-0.192 * * *(-4.118)$ \\
\hline LEV & $0.51(0.998)$ & $0.132 * * *(2.587)$ \\
\hline Age & $0.006(0.162)$ & $-0.061(-1.54)$ \\
\hline ROA & $0.145 * * *(3.227)$ & $-0.087 * *(-2.155)$ \\
\hline Mage & $-0.099 * *(-2.436)$ & $-0.033(-0.826)$ \\
\hline SE & $0.01(0.262)$ & 0.067 \\
\hline R2 & 0.053 & 6.921 \\
\hline F stat & 6.376 & 2.030 \\
\hline D-W & 2.063 & $0.701)$ \\
\hline Note $* * * * *$ and $*$ mean significant at the level of $1 \%, 5 \%$ and $10 \%$, respectively
\end{tabular}

Note: $* * *, * *$ and $*$ mean significant at the level of $1 \%, 5 \%$ and $10 \%$, respectively

paper were processed by means centralization, and then the interaction terms between them were generated, so as to avoid the problem of collinearity and influence the experimental results in this paper. Finally, the regression analysis was carried out.

Before verifying the adjustment effect in this paper, the independent variables and regulatory variables in this

Table 4 Regression result of the regulatory utility model of executive education and tenure

\begin{tabular}{|c|c|c|c|c|}
\hline Variables & ER & EI & ER & EI \\
\hline MH & $0.060(1.443)$ & $0.144 * * *(3.523)$ & $0.177 * * *(3.039)$ & $0.08(1.373)$ \\
\hline Mdegr & $0.134(0.974)$ & $0.539 * * *(3.964)$ & & $-0.022(-0.15)$ \\
\hline Mtime & & & $0.488^{* * *(3.325)}$ & \\
\hline MH*Mdegr & $0.089(0.651)$ & $0.470 * * *(3.474)$ & & $-0.112(-0.764)$ \\
\hline MH*Mtime & & & $0.401 * * *(2.748)$ & $-0.186 * * *(-4.005)$ \\
\hline Size & $-0.171 * * *(-3.611)$ & $-0.208^{* * *(-4.448)}$ & $-0.158^{* * *(-3.412)}$ & $0.127 * *(2.502)$ \\
\hline LEV & $0.051(0.994)$ & $0.13 * * *(2.573)$ & $0.046(0.9)$ & $-0.076^{*}(-1.904)$ \\
\hline Age & $0.008(0.195)$ & $-0.056(-1.440)$ & $-0.011(-0.288)$ & $0.036(0.8)$ \\
\hline ROA & $0.141^{* * *(3.142)}$ & $0.028(0.62)$ & $0.145^{* * *(3.265)}$ & \\
\hline
\end{tabular}




\begin{tabular}{|c|c|c|c|c|}
\hline Mage & $-0.088(0.195)$ & $-0.061(-1.498)$ & $-0.125^{* * *(-3.041)}$ & $-0.107 * *(-2.58)$ \\
\hline SE & $0.008(0.2)$ & $-0.039(-1.987)$ & $0.008(0.202)$ & $-0.026(-0.664)$ \\
\hline R2 & 0.052 & 0.078 & 0.069 & 0.062 \\
\hline F stat & 5.178 & 7.404 & 6.597 & 6.005 \\
\hline D-W & 2.063 & 2.039 & 2.081 & 2.017 \\
\hline
\end{tabular}

Among them, the interaction term (MH*Mdegr) coefficient between executive shareholding and executive education is positive, but it is not significant at the level of $10 \%$. The interaction term $\left(\mathrm{MH}^{*} \mathrm{Mdegr}\right)$ coefficient between executive shareholding and executive education is also positive, but it is significant at the $1 \%$ level. It shows that executive education does not play a moderating effect between executive shareholding and exploratory innovation of enterprises, but executive education plays a moderating effect between executive shareholding and utilization innovation of enterprises. So hypothesis H2a doesn't pass the test, but hypothesis $\mathrm{H} 2 \mathrm{~b}$ does. The main reason may be that the higher the educational level of senior executives, the more likely they are to avoid risks when facing a turbulent external environment, especially high-risk exploratory innovation. On the other hand, the higher the educational level of the senior executives, the slower the group decision-making speed of the senior management team will be, so the more likely to produce invalid decisions, while exploratory innovation often requires the ability to make decisions quickly and seize opportunities.

Among them, the interaction term (MH*Mtime) coefficient between executive shareholding and executive tenure is positive and significant at $1 \%$, indicating that executive tenure plays a moderating effect between executive shareholding and exploratory innovation. In other words, hypothesis $\mathrm{H} 3 \mathrm{a}$ has been verified. However, the interaction term $\left(\mathrm{MH}^{*} \mathrm{Mtime}\right)$ coefficient between executive shareholding and executive tenure is negative and not significant, indicating that executive tenure has no moderating effect between executive shareholding and utilization innovation. In other words, hypothesis $\mathrm{H} 3 \mathrm{~b}$ has not been verified. It may be that the longer the tenure of senior executives, the more experience they have accumulated in the work, the higher their recognition of their own abilities, and the deeper their understanding of the company, the more likely they are to choose exploratory innovation with the characteristics of lag period to satisfy their self-realization value.

\subsection{Robustness test}

In order to make the research results more convincing, this paper carries out robustness tests from the following aspects. First, the regression analysis of the sample data was carried out by replacing the return on net assets in the control variables with the return on total assets. Secondly, some control variables are adjusted and deleted, for example, the incentive control variables of executive compensation are added. Finally, the standard error is adjusted by clustering. The results of regression after adjustment are consistent with the original conclusions of this paper, so it is considered that the conclusions of this paper are relatively robust.

\section{CONCLUSION}

Past on the executives' holdings and enterprise technology innovation, research and development into a lot of research, innovation input, but under the dual innovation perspective, little literature research executive ownership, so this article to a 2015-2018 listed companies as samples, respectively consider executives shareholding of the innovation of enterprise use and explore the influence of the type of innovation, on the basis of general senior education and executive tenure as a moderator variable, to further expand its research framework, verify both between executives shareholding and innovation of the dual role.

Through the above empirical research, it is found that: executive shareholding positively affects enterprise utilization innovation and exploratory innovation, but the influence of executive shareholding on utilization innovation is significant, while the influence on exploratory innovation is not. Executive education promoted the positive influence of executive shareholding on enterprise utilization innovation; The tenure of senior executives can promote the positive influence of senior executives' shareholding on enterprise exploratory innovation. Therefore, enterprises can alleviate the agency problem between managers and owners by increasing the shareholding ratio of senior executives, so that senior executives can have a sense of belonging. And hiring senior executives with higher education degrees to improve the overall soft power of the senior management team. These two ways can promote enterprises to carry out utilization innovation activities and improve the short-term profitability of enterprises through this short-term innovation mode. On the other hand, by extending the tenure of senior executives with shareholding ratio, the enthusiasm of senior executives for exploratory innovation can be promoted, the independent innovation ability of enterprises can be improved, and their core competitiveness can be formed. These conclusions are of great significance for enterprises to enhance their capacity of independent innovation. 


\section{ACKNOWLEDGMENT}

Key Scientific Research Project of Ccolleges
and Universities in Henan Province
(18A630055).

\section{REFERENCES}

[1] Liu xin. Influence of CEO succession selection mechanism based on age perspective on enterprise strategic innovation $[\mathrm{J}]$. Journal of management, 2015,12 (05):668-678.

[2] Harley E. Ryan, Jr. and Roy A. Wiggins. The Interactions between R\& Investment Decisions and Compensation Policy[J]. Financial Management,2002,31(1):5-29.

[3] Hambrick, D.C. Cho, T.S. Chen, M.J. TheInfluence of Top Management Team Heterogeneity on Firms' Competitive Moves[J]. Administrative Science Quarterly,1996,4(41):659-684.

[4] Jiang yaoming, Lai yan. Influence of overseas excutive background on corporate social responsibility information disclosure:the regulating effect of regional regulation pressure [J].Journal of shanxi university of finance and economic,2009,41 (01) :70-86.

[5] Balkin D.B., Mark man G.D., Gomez Mejia L.R.. Is CEO Pay in High Technology Firms Related to Innovation[J]. Academy of Management Journal,2000,43(6):1118-1129.

[6] Hambrick D C, Mason P A. Upper Echelons: The organization as a reflection of its top managers[J]. Academy of Management Review.1984,9(2):193-206.

[7] Talke K, Salomo S, Kock A.Top Management Team Diversity and Strategic InnovationOrientation: the Relationship and Consequences for Innovativeness and Performance[J].Journal of Product Innovation Management,2011,28(6):819-832.

[8] Wang changrong, li na. Research on the relationship between executive characteristics, confidence and enterprise innovation achievements -- based on the empirical data of manufacturing enterprises [J]. Economic issues, 2019 (05):83-90.

[9] Barker, VL.\& Mueller. How national systems differ in their constraints on corporate executives:study of CEO effects in three countries, GC.CEO Characteristics and firm $\mathrm{R} \& \mathrm{D}$ spending $[\mathrm{J}]$. Management Science, 2002(48):782-801.

[10] i jing, Yang jianjun. Status quo and review on the theoretical research of enterprise original innovation $[\mathrm{J}]$. Science and technology management research, 2013, 33(14) : 15-19.

[11] Pan hongliang. The influence of entrepreneurs' absorptive capacity and dual innovation strategy on the growth performance of inborn international enterprises [J]. Science of science and management of science and technology, 2008,39(12):94-110.

[12] DANNEELS E. The dynamic of product innovation and firm competences[J]. Strategic Management Journal,2002,23(12):1095-1121.

[13] Benner M J, Tushman M L. Exploitation, exploration, and process management:The productivity dilemma revisited[J]. Academy of Management Review,2003,28(2):238-256.

[14] Wan xuxian, wang hong, he jia. The influence of financial asset allocation on dual innovation: the regulating effect of executive motivation [J]. Science and technology progress and countermeasures, 2019,36(04):124-132.

[15] Sun Haifa, yao zhenhua, yan maosheng. The influence of demographic characteristics of senior management team on the business performance of textile and information technology companies [J]. Nankai management review, 2006,9(6):61-67.

[16] BANTEL K A, JACKSON S E. Top management and innovations in banking: Does the composition of the top team make a difference?[J]. Strategic Management Journal,2010,10(1):107-124.

[17] Yang yong, da qingli, zhou qin. An empirical study on the impact of corporate governance on technological innovation investment $[\mathrm{J}]$. Science of science and management of science and technology, 2007(11):61-65.

[18] Zhao jie, wei zelong, li yuan. Research on the influence of executive incentive mechanism and combination ability on innovation duality [J]. China science and technology forum, 2012 (02):108-115.

[19] Ryan H.E., Wiggins R.A. The Interactions between $R \& D$ investments and compensation policy[J].Financial management,2002,31(1):5-29.

[20] Zhang zhaoguo, liu yawei, qi xiaolin. Characteristics of managers' backgrounds, promotion incentives and overinvestment [J]. Nankaimanagement review, 2013,16 (04):32-42. 